\title{
Thyrotoxic heart failure: A review of clinical status and meta-analysis of electrocardiogram diagnosis and medical clinical management methods
}

\author{
Aref Albakri* \\ St-Marien hospital Bonn Venusberg, Department of Internal Medicine, Bonn, Germany
}

\begin{abstract}
Heart failure (HF) is the final common pathway of many cardiovascular diseases (CVD). It imposes significant socio-economic and healthcare burden to both patients and healthcare systems. Although the most common cause of HF is ischemic heart diseases, other less common causes such as hyperthyroidism (thyrotoxicosis) should also be considered during diagnosis to improve overall clinical management of HF. Hyperthyroidism is a potentially reversible and curable cause of thyrotoxic HF (THF), which should be excluded in every new patient with HF especially in the absence of coronary artery disease and other structural heart diseases. However, the etiology of thyrotoxic HF remains partially understood - is it the consequence of hemodynamic insult, direct toxic effect or both? Its epidemiology is also difficult to assess because hypertensive, ischemic and other structural heart diseases have not been thoroughly excluded. The present review seeks to aggregate current published evidence on THF to provide a comprehensive understanding of its definition, prognosis, pathogenesis, manifestation, diagnosis and clinical management.
\end{abstract}

\section{Introduction}

Cardiotoxic effects of hyperthyroidism have been described for the several decades and remain the cornerstone for diagnosis and clinical management of thyrotoxic heart failure (THF) [1]. Although thyroid hormones (TH) act on all organs, the heart is particularly vulnerable to even small changes in their serum concentrations. Effects such as increased resting heart rate, myocardial contractility, cardiac output and left ventricular (LV) mass are common consequences of hyperthyroidism [2,3]. However, HF is relatively uncommon in patients with hyperthyroidism after the exclusion of other possible etiologies including coronary artery disease (CAD), ischemic and other structural heart diseases. Thus, research support for THF has lagged far behind that of other more prevalent HF phenotypes such as ischemic and hypertensive HF [4]. The present paper reviews published evidence on clinical definition, epidemiology, etiology, pathophysiology, clinical presentation, diagnosis and clinical management of THF. The review also includes two meta-analyses of THF diagnosis by electrocardiogram and therapeutic methods to improve the understanding of its clinical status as well as clinical management of HF in general.

\section{Definition}

The American Thyroid Association (ATA) and American Association of Clinical Endocrinologists (AACE) Taskforce on hyperthyroidism and other causes of thyrotoxicosis [5] defines thyrotoxicosis as a clinical syndrome characterized by hypermetabolism and hyperactivity because of excessive quantities of circulating free thyroid hormones. The term "hyperthyroidism" refers to a form of thyrotoxicosis characterized by sustained increased in TH biosynthesis and secretion by the thyroid gland [6]. Many patients with thyrotoxicosis may have hyperthyroidism but it is not so in others such as patients in whom thyrotoxicosis results from thyroiditis or exogenous thyroid hormone administration [5,7]. Thyrotoxicosis ranges in severity from subclinical hyperthyroidism to life threatening thyroid storm and ultimately the development of THF [7].

The definitions of thyrotoxicosis and hyperthyroidism are well established but that of its common sequalae (THF) lacks uniformity because of a wide variation in terminologies - hyperthyroidism cardiomyopathy, tachycardiomyopathy, thyrotoxic cardiac disease, thyrotoxic cardiomyopathy or thyrotoxic HF. The report of the 2016 World Health Organization (WHO)/International Society and Federation of Cardiology (ISFC) proposed a widely cited definition. It is a form of HF characterized by myocardial damage secondary to the toxic effect of abundant serum free $\mathrm{TH}$ leading to altered energy production by cardiomyocyte (oxidative phosphorylation glycolysis), intracellular metabolism (protein synthesis) and myofibril contractile function [8]. Its typical manifestations include LV hypertrophy (LVH: increase in LV mass), tachycardia, atrial fibrillation (AF), dilated cardiac chambers, pulmonary hypertension $(\mathrm{PH})$ and diastolic dysfunction [9$11]$.

\section{Epidemiology}

The epidemiology of THF is partially understood because of difficulty in its clinical assessment caused by the lack of thorough exclusion of other potential etiologies such as concomitant hypertensive, ischemic

${ }^{\star}$ Correspondence to: Aref Albakri, St-Marien hospital Bonn Venusberg, Department of Internal Medicine, Bonn, Germany, E-mail: arefalbakri@yahoo.com

Key words: hyperthyroidism, tachycardiomyopathy, thyrotoxic cardiac disease, thyrotoxic cardiomyopathy, thyrotoxic heart failure

Received: December 10, 2018; Accepted: December 18, 2018; Published: December 24, 2018 
and other structural heart diseases [4]. In addition, HF is relatively uncommon in patients with thyrotoxicosis or hyperthyroidism [7] and thus THF lacks population-based epidemiological studies useful in establishing its prevalence and incidence. The few studies examining incidence and prevalence of THF provide a wide variation. In three clinical trials, the prevalence of THF varied from $12 \%$ to $68 \%$ in hyperthyroid patients [12-14]. Other studies report incidence of adverse cardiovascular effects associated with THF in patients with thyrotoxicosis or hyperthyroidism. Up to $90 \%$ of patients with thyrotoxicosis may develop AF, 47\% LV systolic dysfunction and $1 \%$ dilated THF and a third of these cases are reversible [15]. The prevalence of $\mathrm{PH}$ is $29 \%$ in subclinical thyrotoxicosis and $39.6 \%$ in overt thyrotoxicosis is 23 [11] and mitral valve prolapse ranges from $18 \%$ to $41 \%$ in thyrotoxicosis patients compared to $6 \%$ to $20 \%$ in the general population [16-18]. Although the incidence of heart rhythm disturbances in thyrotoxicosis also varies widely, tachycardia is a typical symptom at rest and the most common heart rhythm disturbance occurring in $42 \%$ to $73 \%$ in thyrotoxic patients $[19,20]$.

\section{Prognosis}

THF is a threatening cardiac complication of thyrotoxicosis associated with an elevated risk of disability and mortality [7]. Traditionally, prognosis of THF was considered favorable because of potentially high reversibility of ventricular function after quick establishment of euthyroid state [11]. However, recent long-term follow-up studies demonstrate an incomplete reversal of ventricular function or myocardial alterations in THF patients. Some irreversible histological changes in the myocardium in patients who had THF were detected in necrosis of hypertrophied cardiomyocytes and fibrotic development [21]. In addition, one case report suggested radioimmunologic imaging with antimyosin antibodies in a THF patient detect the presence of myocardial fibrosis [22].

Current evidence also suggests a less favorable prognosis in THF patients including those successfully treated. Mortality in THF patients is 1.2 higher than in patients with hypertension, valvular heart disease or CAD and 1.4 higher than in the general population [23]. Persistence in cardiovascular complications predicts poor prognosis associated with increased risk of death [24]. In a British study, patients $>60$ years with thyrotropin stimulating hormone (TSH) less than normal values had twice mortality rates compared to euthyroid subjects with cardiovascular diseases, suggesting TSH is the principal cause of THF [11]. Cardiovascular complications of thyrotoxicosis are important prognostic predictors and therapeutic targets for the management of THF.

Predictors of ominous prognostic (development of HF) in patients with thyrotoxicosis are partially understood. Siu et al. [15] reported 5.8\% of patients with thyrotoxicosis develop HF independently predicted by AF, high serum TSH concentration and ventricular dysfunction. The male gender was also associated with significant risk of developing HF. Left ventricular (LV) dysfunction and cardiac chamber dilation are also common in about a third of patients with restored euthyroidism [15]. Patients with preserved ejection fraction (55\% vs. 30\%) and lower New York Heart Association Functional (NYHA) class have significantly better outcomes (reversed changes) [11]. Other important predictors of the development of HF in thyrotoxic patients defined by multifactorial analysis include the duration of hyperthyroidism, systolic blood pressure (BP), high concentration of free $\mathrm{T}_{3}$ serum levels before treatment, LV dilations and to some extent dilation of other cardiac chambers, and clinical manifestations such as left atrial dilation, AF, and LV hypertrophy [15].

\section{Etiopathophysiology}

\section{Thyroid homeostasis}

Thyroid hormone homeostasis is essential for the optimal functioning of the heart. Thus, thyroid dysfunction, present in 5-10\% of the population with a higher prevalence in women and patients $>$ 60 years, is the principal cause of THX $[25,26]$. The classic feedback loop mechanism regulates thyroid homeostasis. The thyroid gland secretes to active hormones: thyroxine $\left(\mathrm{T}_{4}\right)$ - a prohormone and triiodothyronine $\left(\mathrm{T}_{3}\right)$, acting as the final mediator. The two hormones regulate pituitary synthesis and the release of thyrotropin, which is a thyroid-stimulating hormone (TSH) [27,28]. In hypothyroidism, the lack of $\mathrm{T}_{4}$ feedback leads to high TSH levels $>20 \mathrm{mIU} / \mathrm{L}$, whereas in subclinical hypothyroidism, the TSH levels range from 3 to $20 \mathrm{mIU} / \mathrm{L}$ with normal $\mathrm{T}_{4}$ and $\mathrm{T}_{3}$ levels $[29,30]$. Conversely, in hyperthyroidism, TSH levels $<0.1 \mathrm{mIU} / \mathrm{L}$. in such patients, there is excessive production of $\mathrm{T}_{3}$ because of hyper-secretion by the thyroid gland leading to increased peripheral monodeiodination of $\mathrm{T}_{4}$ resulting in profound changes in the cardiovascular system, which could be normal or pathologic [28].

\section{Molecular mechanism of thyroid action}

The exact cellular and molecular mechanisms by which thyroid hormones exert their action on the cardiovascular system has been well established [31,32]. The thyroid gland synthesizes $\mathrm{T}_{4}$ and $\mathrm{T}_{3}$ in response to $\mathrm{TSH}$. The thyroid gland primarily secretes $\mathrm{T}_{4}(\sim 85 \%)$ and monodeiodination in the liver, kidney and skeletal muscle converts $\mathrm{T}_{4}$ into $\mathrm{T}_{3}[33,34]$. Both circulating $\mathrm{T}_{3}$ and $\mathrm{T}_{4}$ diffuse easily across the cytoplasmic membrane of target cells including cardiomyocytes. Due to the lack of significant cardiomyocyte intra-cellular deiodinase activity, the heart mainly relies on plasma $\mathrm{T}_{3}$. The effect of $\mathrm{T}_{3}$ on cardiac function occurs through positive or negative regulation of the expression of key structural and regulatory genes (Table 1 ). The presence of $\mathrm{T}_{3}$ induces increased transcription of positively regulated cardiac genes while represses the expression of negatively regulated genes.

Through the regulation of key structural and regulatory cardiac genes, $\mathrm{T}_{3}$ hormone exerts its effect on the cardiomyocyte to regulate cardiac function. Myosin heavy chain genes encode contractile protein isoforms of the thick filament in the cardiomyocyte. The sarcoplasmic reticulum $\mathrm{Ca}^{2+}$-ATPase and its inhibitor pholamban regulate intracellular calcium cycling. Together, these genes are responsible for increased cardiac contractile function and diastolic relaxation [35-37]. Hormone $\mathrm{T}_{3}$ also exerts effect on the cardiomyocyte and systemic vascular through extra-nuclear non-genomic effects. These effects include changes in $\mathrm{Na}, \mathrm{K}$ and $\mathrm{Ca}$ membrane ion channels, actin polymerization, adenine nucleotide translocator in the mitochondrial membrane, and many other intracellular signaling pathways in the heart and vascular smooth muscle cells [38-40]. Both $\mathrm{T}_{3}$-mediated genomic and non-genomic effects act in concert to regulate cardiac function and cardiovascular hemodynamics [11]. The mechanism of thyroid

Table 1. Effect of Tri-iodothyronine $\left(\mathrm{T}_{3}\right)$ hormone on cardiac gene expression

\begin{tabular}{|c|c|}
\hline Positively Regulated & Negatively Regulated \\
\hline Alpha-myosin heavy chain & Beta-myosin heavy chain \\
\hline Sarcoplasmic reticulum $\mathrm{Ca}^{2+}$ ATPase & Phospholamban \\
\hline $\mathrm{Na}^{+} / \mathrm{K}^{+}$-ATPase & Adenylyl cyclase catalytic sub-units \\
\hline Beta1-Adrenergic receptor & Thyroid hormone receptor alpha-1 \\
\hline Atrial natriuretic hormone & $\mathrm{Na}^{+} / \mathrm{Ca}^{2+}$ exchanger \\
\hline $\begin{array}{c}\text { Voltage-gated potassium channels } \\
(\mathrm{Kv} 1.5 / 4.2 / 4.3)\end{array}$ \\
\hline
\end{tabular}

Adapted from Klein \& Danzi, 2007, p. 1727 [27] 
action affects cardiac function and peripheral vasculature in three main processes: hemodynamics (mainly on peripheral circulation), myocardial contractility and heart rate (Figure 1).

Effects on hemodynamics: Thyroid hormone decreases the resistance in peripheral arterioles through a direct effect on vascular smooth muscle cells (SMCs) and decreased mean arterial pressure. These changes result in increased heart rate, a selective increase in blood flow to certain organs and a drop in diastolic pressure with widening of the pulse pressure [11]. Vasodilation accompanied with no actual rise in renal blood flow causes the activation of the reninangiotensin-aldosterone system (RAAS) and increased renal $\mathrm{Na}^{+}$ absorption. At the same time, $\mathrm{T}_{3}$ increases erythropoietin synthesis resulting into increased red cell mass. Together, these changes promote an increase in blood volume and preload (LVEDV and LVESV), and in hyperthyroidism, increased in cardiac output ranges between $50 \%$ and $300 \%$ higher than in normal individuals [41]. Thyroid-hormone mediated effect on the vascular SMCs are the consequence of genomic and non-genomic processes. Non-genomic processes act on membrane ion channels and endothelial nitric oxide (NO) synthase leading to decreased systemic vascular resistance (SVR) $[42,43]$. Relaxation of the vascular SMCs leads to decreased arterial resistance ultimately increasing cardiac output. Increased secretion of endothelial NO results partly from $\mathrm{T}_{3}$-mediated effects on the protein-kinase akt pathway via non-genomic or genomic actions [44]. Endothelial NO synthesis acts in a paracrine manner on adjacent vascular SMCs to promote vascular relaxation

Effects on contractility: Thyroid hormone regulates important cardiac gene expressions. Many cardiac manifestations of thyrotoxicosis have been associated with changes in T3-mediated gene expression [4547]. Human and experimental animal studies report hyperthyroidism leads to ventricular hypertrophy because of increased cardiac work due to increased hemodynamic load [48-50]. Thyroid hormone mediates the expression of regulatory and structural genes in the cardiomyocyte

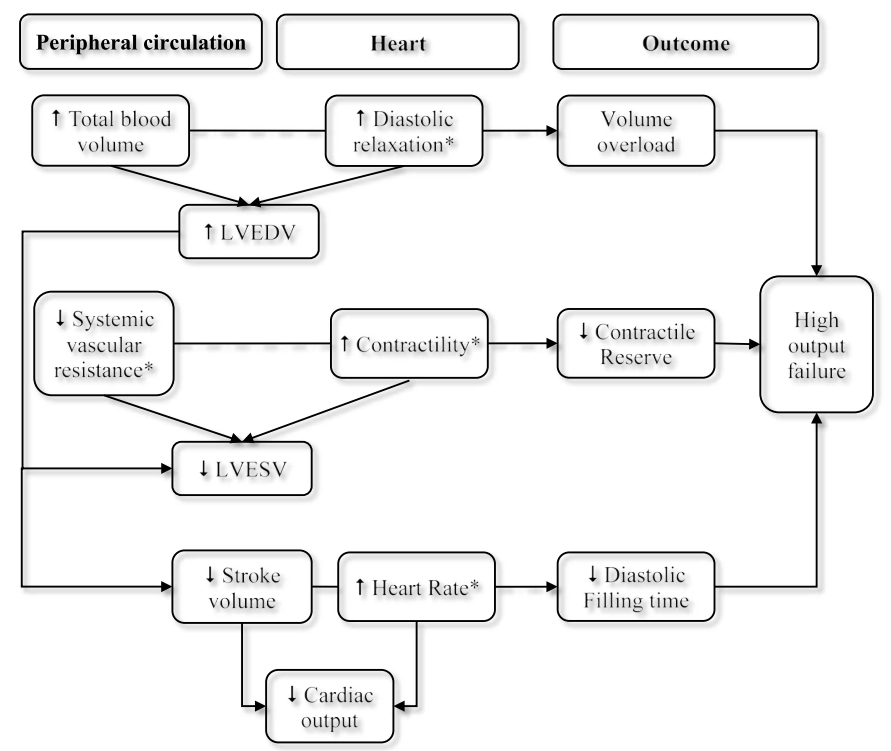

Figure 1. Effect of $\mathrm{T}_{3}$ hormone on cardiac function

Tri-iodothyronine $\left(\mathrm{T}_{3}\right)$ hormone causes thyrotoxic heart failure (THF) through its actions on peripheral circulation and heart leading to increased cardiac output, volume overload, contractile impairment, and reduced diastolic filling. LVEDV: Left Ventricular End Diastolic Volume; LVESV: Left Ventricular End Systolic Volume; $\uparrow$ Increased; $\downarrow$ Decreased; Solid arrows: Direct effects; Dashed arrows: Potential outcomes; *Features for which $\mathrm{T}_{3}$ is directly responsible, Reproduced from Toft \& Boon, 2000, p. 455 [28]
(Table 1). Direct effects involve transcription of genes regulating the function of cardiomyocytes, vascular SMCs and other structural cardiac units [41]. $\mathrm{T}_{3}$ enters cardiomyocytes via specific transporters on the cell membrane and binds thyroid hormone receptors (THR) in the nucleus. THR bind specific thyroid hormone response elements (TRE) to mediate induction of transcription in positively regulated genes [28]. Gene transcription is higher in regions encoding alphamyosin heavy chains, Sarcoplasmic reticulum $\mathrm{Ca}^{2+}$-ATPase, $\mathrm{Ca}^{2+}-\mathrm{K}^{+}$ATPase, beta-adrenergic receptors, troponin 1 and $\mathrm{Ca}^{+}$uretic peptide. High levels of TH affect the expression of myosin isoforms leading to enhanced synthesis of MNC-alpha/alpha myosin chains, in which ATPase is more active leading to increased myofibril contractions [41]. Finally, thyrotoxicosis may cardiac function by increasing myocardial energy consumption. The number of mitochondria and their functional activity increases resulting into enhanced adenosine triphosphate (ATP) production. In patients with severe thyrotoxicosis, myocardial oxygen consumption increases but the efficiency of utilization decreases significantly. The decrease is linked to altered oxidative phosphorylation due to abnormal oxidative-enzyme activity (reduction in myocardial ATP and creatine phosphate levels in glycolysis activation) [11].

\section{Pathogenesis of arrhythmias}

Tachycardia: Tachycardia is a cardinal feature of thyrotoxicosis. It results from faster diastolic depolarization linked to shortening of the action potential duration of the sinoatrial node [23]. The effect of $\mathrm{TH}$ on pacemaker and conductive cardiac system include acceleration of systolic and diastolic depolarization, shortening of action potential and refractory period of atrial and atrioventricular myocytes associated with increased AF occurrence [51]. TH also regulates some myocardial genes that encode synthesis of ion channels in cell membrane affecting altering their activities and T3 non-genomic cell effects such as the regulation of intracellular levels and their intra-cellular distribution leading to shortened action potential [11].

Atrial fibrillation: Atrial disturbance such as AF and atrial premature heartbeats is higher in thyrotoxicosis while the rate of ventricular arrhythmias is comparable to that of the general population [52]. Sensitivity to TH by atrial and ventricular myocardium may be the cause of the variation of the atrial and ventricular arrhythmias. Atrial sensitivity to arrhythmogenic TH effects results from high betaadrenoreceptors density at the surface of atrial cardiomyocytes is twice as high as in the LV. Since androgens up-regulate the expression of beta-adrenoreceptors genes leading to increased density, males are at a higher susceptibility to rhythm disturbance compare to females [11].

Hypertension: Systolic hypertension occurs in up to one-third of patients with hyperthyroidism especially in the elderly. Hypertension may be partly a consequence of the inability of the vascular system to accommodate increased stroke volume [11]. The fall in systemic vascular resistance leads to a decrease in diastolic BP and explains the low mean arterial pressure and the uncommon manifestation of diastolic hypertension in patients with hyperthyroidism. However, a complete reinstatement of euthyroid state leads to a complete reversal of these changes $[27,28]$.

In sum, HF in patients with thyrotoxicosis may develop through two main pathways. The first through tachycardia-induced HF with $\mathrm{LV}$ dysfunction is the most common in AF patients. The second through RV heart failure resulting from volume overload of the RV due to increased circulating blood volume and venous return. Its main characteristics include RV dilatation, enlarged tricuspid valve ring 
and tricuspid insufficiency very common in patients with pulmonary hypertension [52].

\section{Clinical presentation}

Heart failure in patients with thyrotoxicosis is progressive and may be classified into three stages. (a) Hyperkinetic characterized by preserved LV function and LV effusion fraction; (b) Normokinetic characterized by compensatory stage with reversible myocardial hypertrophy and preserved cardiac output; and (c) hypokinetic stage characterized by decompensated stage with low cardiac output and stroke volume with reversible or irreversible cardiac chamber hypertrophy and dilatation [11]. THF is more common in the elderly population who usually present with co-occurring cardiovascular diseases such as $\mathrm{CAD}$, valvular heart disease and arterial hypertension) leading to functional and structural cardinal alterations. Thus, the elderly are highly susceptible to impairment of myocardial contractility in the presence of hyperthyroidism-associated increased myocardial load $[27,28]$. Conversely, younger patients without cardiovascular pathology usually develop high output HF characterized by myocardial hyper-contractility. However, they may also develop HF with low output and dilated heart chambers in case of chronic severe thyrotoxicosis but the underlying mechanisms are not fully understood [53].

The most common symptoms in THF patients include palpitation, cardialgia (cheat pain), dyspnea, and irregular heartbeat. Common findings at physical examination include arrhythmias, systolic hypertension, orthostatic hypotension, heart enlargement and bubbling rales. Sign of THF include tachycardia at rest and during sleep, and significantly increased heart rate at minimal physical exertion. Patients usually present with heart rate of 120-240 beats per minute (bpm) at rest and up to $160 \mathrm{bpm}$ at physical or emotional exertion and complains of pulsation in the neck, head and abdomen. Atrial fibrillation is common in THF patients as well as patients with clinical and subclinical thyrotoxicosis. Thus, thyrotoxicosis should be excluded in all AF patients refractory to antiarrhythmic medication. Water retention is usual and edema can be present even in THF with preserved ejection fraction. If symptoms are refractory after optimal treatment of thyrotoxicosis, concomitant cardiovascular pathology should be excluded. Healthy individuals may have palpitation usually associated with females and older adults $>50$ years while dyspnea is associated with females and elevated levels of T4 $>30 \mathrm{pmol} / \mathrm{l}$. following restoration of euthyroid state, dyspnea could persists in patients who smoke [54].

\section{Diagnosis}

Expert consensus on clinical guidelines for the diagnosis of THF are lacking. The principal reason for the lack of guidelines is the exclusion of THF in the classification of HF as a definite clinical form of HF. Instead, the WHO/ISFC Task Force classify THF as a form of cardiomyopathy (thyrotoxic cardiomyopathy) [8]. Such a classification focuses more on myocardial alterations and less on hemodynamic dysfunction, both of which are the most common pathological features of THF $[27,33,34]$ and has less relevance to guide specific clinical management of THF. On the other hand, the ESC only recommends clinical guidelines for diagnosis of HF in general with no specific criteria for THF diagnosis [55]. Current diagnosis strategies for THF is by determining the levels of TSH and by exclusion of other causes of structural and functional cardiac alterations. Common diagnostic methods and tools are assessment of patient history, physical examination, electrocardiography and cardiac imaging for the assessment of structural and functional alterations in ventricular and atrial myocardium.

\section{Diagnostic strategies}

Patient history: The ESC HF guidelines recommend obtaining detailed patient history at presentation for patients suspected with HF [55]. Patient history is useful to evaluate symptoms and duration related to hyperthyroidism, which is a marker for poor prognosis. It is also useful to rule out known cardiovascular diseases such as ischemic heart disease, rheumatic heart disease, hypertension, diabetes, drug intake and other cardiac and systemic disorders that could cause structural or functional cardiac alterations [56]. Table 2 summarizes the main differences between THF and HF due to other causes.

Laboratory tests: The ATA/AACE Taskforce on hyperthyroidism recommend the measurement of circulating TSH rather than direct thyroid hormones as the initial screening test for diagnosing hyperthyroidism [5,7]. Measuring circulating TSH levels has the highest sensitivity and specificity of any single blood test for the assessment of suspected hyperthyroidism. However, diagnostic accuracy significantly improves by measuring both circulating TSH and free $\mathrm{T}_{4}$ at the time of initial evaluation. Since the relationship between free $\mathrm{T}_{4}$ and TSH is an inverse log-linear, small changes in free $\mathrm{T}_{4}$ causes large changes in TSH. Diagnosis should distinguish between normal TSH levels $(>0.1 \mathrm{mU} / \mathrm{l})$ from low levels $(<0.1 \mathrm{mUA})$ and undetectable levels $(<$ $0.01 \mathrm{mUA}$ ) [57,58]. Low or undetected levels confirm the diagnosis of hyperthyroidism. When $\mathrm{T}_{3}$ and $\mathrm{T}_{4}$ levels fall within normal limits indicates the presence of subclinical and occult hyperthyroidism. Although measurement of $\mathrm{T}_{3}$ is useful to detect patients with $\mathrm{T}_{3}$ toxicosis, the tests are complex and usually not required $[58,59]$. In addition, measurement of total $\mathrm{T}_{4}$ and $\mathrm{T}_{3}$ alone is not recommended because of potentially misleading findings in elderly patients [57].

Electrocardiography: Electrocardiography (ECG) is one of the most basic non-invasive diagnostic tool used for assessing cardiac function. ECG records the electrical activity of the heart generated by depolarization of the heart muscle [60]. In patients with THF, ECG is used to assess cardiac manifestations of thyroid disorders. While consensus on ECG changes associated with THF have not been published, current evidence from clinical trials and case series suggest common ECG changes in hyperthyroidism include sinus tachycardia (the most common), arrhythmias, non-specific T-wave changes and STsegment changes (LV strain) [60,61]. ECG changes are non-specific but useful to increase clinical suspicion of THF. ECG changes are reversible after achievement euthyroid state [11].

Echocardiography: Echocardiography is a widely available, easily accessible and cost-effective non-invasive imaging modality used assessing structural and physiological functioning of the heart. In THF patients, echocardiographic examination of the LV function is useful in the assessment of cardiac effect of thyrotoxicosis [58]. At present, there are no specific echocardiographic parameters or values for the diagnosis of THF. However, there are suggested echocardiographic parameters and cut-off values derived from HF clinical guidelines $[5,7,55]$ and clinical trials on other phenotypes such as high output HF $[58,59,62-64]$ as summarized in Table 3.

Table 2. Differences between thyrotoxic and non-thyrotoxic heart failure

\begin{tabular}{|c|c|c|}
\hline Features & Thyrotoxic Heart Failure & $\begin{array}{c}\text { Non-Thyrotoxic Heart } \\
\text { Failure }\end{array}$ \\
\hline Myocardial contractility & Increased & Reduced \\
\hline Cardiac output & High & Low \\
\hline Tachycardia & Tachycardia leads to HF & HF leads to tachycardia \\
\hline Arrhythmias & Atrial & Ventricular \\
\hline Hypertension & Systolic with pulse pressure & Diastolic \\
\hline
\end{tabular}

Adapted from Osuna et al. 2017, p. 61 [3] 
Table 3. Echocardiographic parameters in diagnosis of thyrotoxic heart failure

\begin{tabular}{|c|c|}
\hline Parameters & Description \\
\hline LV systolic dysfunction & $\begin{array}{l}\mathrm{LVEF}<50 \% ; \text { LVFS }<30 \% \text {; cardiac index }<2.8 \mathrm{~L} / \mathrm{min} / \mathrm{m}^{2} \\
\mathrm{CO}<4 \mathrm{~L} / \mathrm{min} \text {; }\end{array}$ \\
\hline LV diastolic dysfunction & $\begin{array}{l}\mathrm{E} / \mathrm{A}<1.1 \text {; isovolumic relaxation time }>90 \mathrm{msec} ; \mathrm{E} \text { wave } \\
\text { deceleration time }>210 \mathrm{msec} \text {; peak filling rate }<5 \text {. }\end{array}$ \\
\hline $\begin{array}{l}\text { Increased systolic function } \\
\text { (myocardial contractility) }\end{array}$ & $\begin{array}{l}\mathrm{EF}>75 \% ; \mathrm{FS}>42 \% ; \mathrm{CO}>7 \mathrm{~L} / \mathrm{min} ; \text { peak aortic systolic } \\
\text { velocity }>120 \mathrm{~cm} / \mathrm{sec}\end{array}$ \\
\hline $\begin{array}{l}\text { Increased diastolic } \\
\text { function }\end{array}$ & $\begin{array}{l}\text { E wave velocity }>72 \mathrm{~cm} / \mathrm{sec} ; \text { A wave velocity }>59 \mathrm{~cm} / \mathrm{sec} \text {; } \\
\text { isovolumic relaxation time }<76 \mathrm{msec} \text {; E wave deceleration } \\
\text { time }<179 \mathrm{msec}\end{array}$ \\
\hline $\begin{array}{l}\text { Left ventricular mass } \\
\text { index }\end{array}$ & LVMI normal 43-96 g/m² (women) and 49-116 g/m² (men) \\
\hline Relative wall thickness & $\begin{array}{l}>0.43 \text { (concentric hypertrophy); }<0.43 \text { (eccentric } \\
\text { hypertrophy) }\end{array}$ \\
\hline
\end{tabular}

E/A: Early diastolic velocity/velocity with atrial contraction CO: Cardiac Output; LVEF: Left Ventricular Ejection Fraction; LVFS: Left Ventricular Fractional Shortening

Common echocardiography findings in THF patients are LV hypertrophy (including posterior wall and inter-ventricular septum thickening), elevated LV end-diastolic volume and LV myocardial mass. Mitral valve prolapse is also a common finding in THF patients. THF patients with dilated thyrotoxic cardiomyopathy exhibit dilation of all cardiac chambers and decreased LV systolic function (LVEF).

Other typical findings of radiological imaging in THF patients include dilation of both ventricles and conus pulmonalis expansion found in patients with severe thyrotoxicosis. Expansion of conus pulmonalis and RV enlargement form mitral configuration of the heart with no LA enlargement. Pulmonary edema is another radiological sign in thyrotoxicosis. Cardiac perfusion scintigraphy using thallium chloride 201 exhibits diffuse or small-focal decrease of cardiomyocyte metabolism. This method allows evaluation of intact cardiomyocyte useful for excluding myocardial damage at subclinical phase of the disorder. Stress echocardiography may be used to assess functional myocardial reserve. However, higher levels of TH and TSH together with the reversal of cardiac alterations after normalization of $\mathrm{TH}$ hormones is critical to confirm diagnosis of THF [11].

\section{Meta-analysis of ECG changes in thf patients}

Confirmatory diagnosis of THF relies on the exclusion of other causes of structural and functional cardiac alterations together with evidence of higher levels of circulating free TH and TSH, and reversal of cardiac changes following the achievement of euthyroidism (normalization of TH hormones) [27,28]. Although non-specific, ECG changes play an important role in identifying patients for further cardiac imaging assessment. However, ECG changes associated with THF are not well established, with a majority of studies being case reports and series. The present meta-analysis seeks to pool together findings from published clinical trials to determine common ECG changes valuable in the diagnosis of THF with the aim of improving THF diagnosis and guide clinical management approaches.

Search criteria and inclusion: A computer-aided search of online databases PubMed and EMBASE was performed to identify published studies evaluating ECG in diagnosis of THF. The key search terms used were thyrotoxic heart failure, hyperthyroidism, thyrotoxicosis, diagnosis and electrocardiogram. Bibliographies of included studies and review articles and editorial were also screened to identify additional eligible studies missed by the initial online search. Two investigators performed the study selection independently. The main inclusion criteria were the study: (a) included patients with thyrotoxicosis or hyperthyroidism and heart failure; (b) evaluated cardiac function and structure using ECG; and (c) reported number of patients with positive diagnosis for ECG. The exclusion criteria was case studies, case reports, review articles, editorials and studies without statistical analysis. There was no restriction on publication year or language. Two investigators independently reviewed titles and/or abstracts from the initial search to determine whether the inclusion were satisfied. The full text of the study was obtained when the article could not be excluded with certainty. The decision for inclusion was decided separately, results compared and any discrepancy resolved by consensus.

Clinical heterogeneity was assessed in terms of difference between studies in patient population and in the context of care. The degree of heterogeneity across studies was calculated using the $\mathrm{I}^{2}$ statistic. A random model effect was used when $\mathrm{I}^{2}>50 \%$ and a fixed model when $\mathrm{I}^{2}<50 \%$. Proportions of patients of interest was re-calculated from relevant numerator and denominator, and the overall proportion was derived using meta-analysis techniques and presented along with $95 \%$ confidence intervals $(95 \% \mathrm{CI})$ calculated using a normal approximation. Two reviewers extracted data independently and resolved any discrepancy by consensus. The extracted data included study details (author and publication year), patient characteristics (population, mean age and the male proportion) and clinical outcomes (Tables 4 and 5).

Study characteristics and outcomes: The initial online search yielded 551 studies. After the application of the inclusion criteria against titles, abstract and full-text, five studies published between 1960 and 2016 were finally included in this meta-analysis [56,61,65-67]. Patients included exhibited signs and symptoms of overt hyperthyroidism and HF [65-67] or thyroid disorders with cardiovascular manifestations $[56,61]$. The five studies had a combined patient population of 585, mean age 45 years, with a greater female proportion (67\%). Analysis of pooled data indicates sinus tachycardia is the most common ECG changes in THF patients (47.1\%) followed by ST-T changes $(20.8 \%)$, prolonged QT interval (14.0\%) and AF (8.4\%) as summarized in Table 6 and Figure 2. Data from three studies $[56,61,67]$ indicate LVH is also common to $16.9 \%$ of THF patients.

Discussion: The literature on ECG changes in thyrotoxicosis patients is extensive but has little meaningful information to assist clinicians in the diagnosis and care of THF patients. Several non-specific ECG changes have been reported but there is a general disagreement on their incidence and relation to adverse cardiac manifestations in THF

Table 4. Summary of study and patient characteristic

\begin{tabular}{|l|c|c|c|c|l|}
\hline First Author [Ref\#] & Year & Sample & $\begin{array}{c}\text { Female } \\
\mathbf{( \% )}\end{array}$ & $\begin{array}{c}\text { Age } \\
(\mathbf{y r s} .)\end{array}$ & Patient Selection \\
\hline Hoffman et al. [65] & 1960 & 123 & 80 & NR & $\begin{array}{l}\text { Overt } \\
\text { Hyperthyroidism }\end{array}$ \\
\hline Parisi et al. [66] & 1974 & 17 & 39 & 53 & Overt Thyrotoxicosis \\
\hline Osman et al. [67] & 2007 & 393 & 79 & 49 & $\begin{array}{l}\text { Overt } \\
\text { hyperthyroidism }\end{array}$ \\
\hline Satpathy et al. [61] & 2013 & 28 & 57 & NR & Thyroid disorders \\
\hline Goyal et al. [56] & 2016 & 24 & 79 & 34 & Thyroid dysfunction \\
\hline
\end{tabular}

Table 5. Summary of clinical outcomes of ECG assessment on THF patients

\begin{tabular}{|l|c|c|c|c|c|}
\hline First Author [Ref\#] & Sinus Tarchycardia & LVH & $\begin{array}{c}\text { Prolonged } \\
\text { QT Interval }\end{array}$ & ST-T changes & AF \\
\hline Hoffman et al. [65] & 46 & NR & 18 & 28 & 15 \\
\hline Parisi et al. [66] & 8 & NR & NR & NR & NR \\
\hline Osman et al. [67] & NR & 7 & NR & NR & 24 \\
\hline Satpathy et al. [61] & 17 & 12 & 8 & 6 & 6 \\
\hline Goyal et al. [56] & 19 & 4 & 0 & 2 & 3 \\
\hline
\end{tabular}

AF: Atrial Fibrillation; LV: Left Ventricular; LVH: Left Ventricular Hypertrophy 
Table 6. Proportion of patients with ECG changes

\begin{tabular}{|c|c|c|c|c|}
\hline Pooled Data (Total) & Sinus Tarchycardia (\%) & Prolonged QT Interval (\%) & ST-T Changes & (\%) \\
\hline Fixed Effect & $47.09(39.94-54.33)$ & $14.00(9.27-19.99)$ & $20.80(15.09-27.51)$ \\
\hline Random Effect & $55.37(35.64-74.26)$ & $12.52(2.05-30.01)$ & $19.91(12.79-28.15)$ \\
\hline $\mathrm{I}^{2}$ (Inconsistency) & $82.78(55.92-93.28)$ & $83.61(50.51-94.57)$ & $27.00(0.00-97.55)$ \\
\hline
\end{tabular}
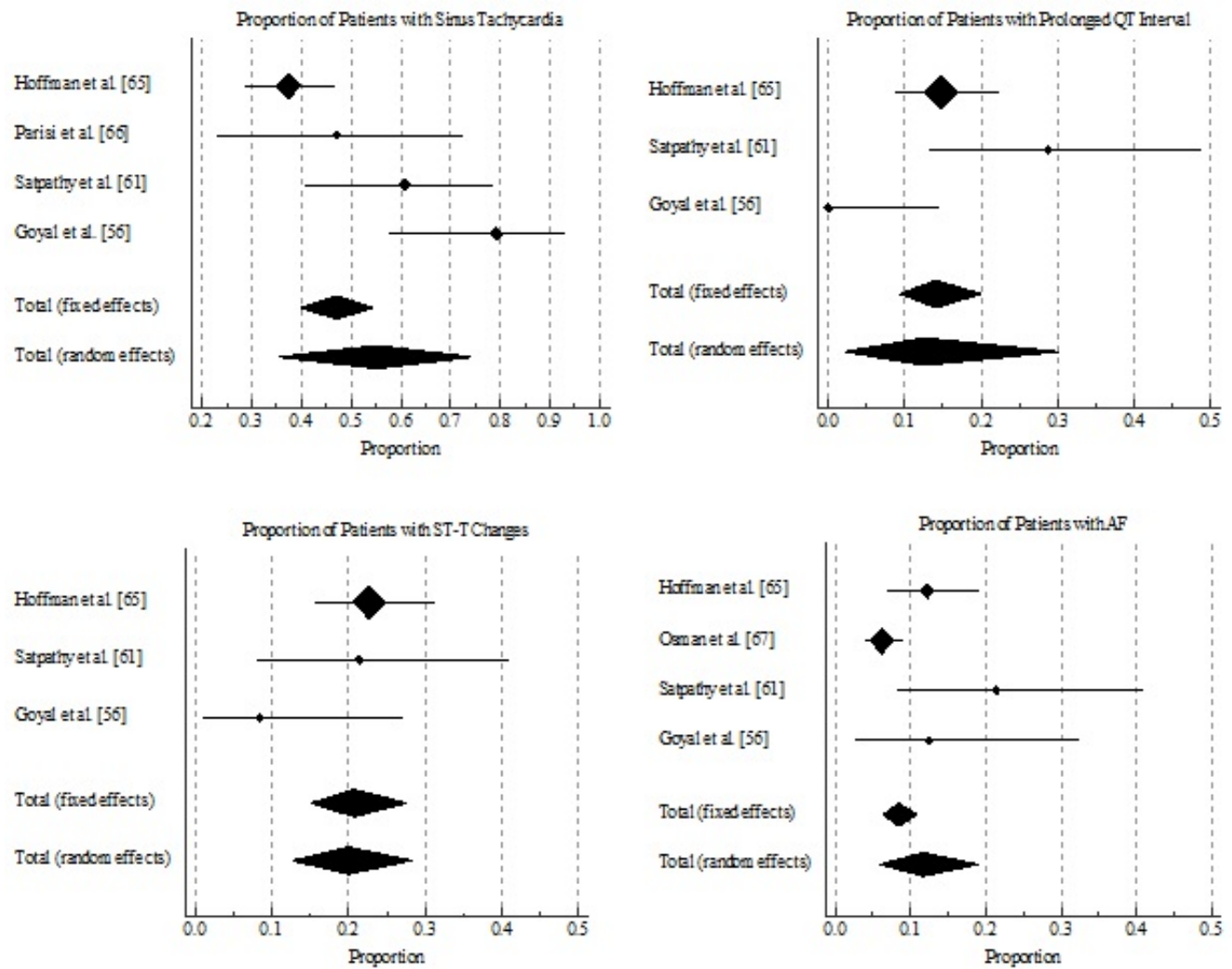

Figure 2. Forest plot showing proportion of patients with ECG changes

patients. These ECG changes include sinus tachycardia, AF, prolonged atrioventricular conduction, increased P-wave duration and amplitude, LVH and non-diagnostic T-wave changes [60,61]. However, sinus tachycardia and AF are usually accompanies THF but other ECG changes are rare, or could be associated with myocardial damage or the effects of medication such as digitalis [65]. Although non-specific, ECG changes are valuable to increase clinical suspicion of THF $[7,11]$. The present meta-analysis thus sought to determine common ECG changes in THF patients. We find sinus tachycardia is the most common ECG change in THF patients, which is present in almost half of THF patients. Other changes are ST-T changes, prolonged QT interval and AF. However, these findings may be interpreted with caution because the present analysis relied on only five studies that included a small sample of 585 patients and the criteria for inclusion of patients in the individual studies was mainly thyrotoxicosis with cardiac manifestations. These criteria does not represent all the clinical manifestations of THF and may not fully apply to THF patients.

Sinus tachycardia and AF have been demonstrated as typical ECG changes in THF patients and consequently have been recommended as part of the initial ECG assessment in thyrotoxic patients suspected with HF [5,7]. In our analysis, the proportion of THF patients with AF was relatively low (8\%). However, the low findings could be explained by the relatively younger population included in the individual studies. The presence of AF in THF has been associated with older age and lower prevalence in younger populations [56]. In addition, since the included population was basically overt thyrotoxicosis or hyperthyroidism, the presence of other ECG tests such as ST-T changes and prolonged QT interval may not be accurately expressed. In THF patients, the typical clinical manifestations are myocardial damage and higher cardiac output, which may induce greater ECG changes. In addition, since THF often co-occurs with ischemic or other structural heart disease, ECG changes are largely non-specific. However, since ECG changes revert to normal after establishment of euthyroid state [11], serial ECG assessment may be useful to provide prognostic information as well as assist in monitoring treatment effectiveness. In summary, our findings demonstrate the value of ECG associated sinus tachycardia and AF in increasing clinical suspicion of THF indicating the need for further diagnostic tests.

\section{Clinical management}

Clinical management of THF lacks specific treatment guidelines and protocols. In addition, management is difficult because THF represents a heterogeneous clinical entity. The majority of patients are older, often with co-existing cardiovascular diseases and associated tachyarrhythmias [10]. However, because of the potential reversal of symptoms and normalization of cardiac structure and function after the achievement of euthyroid state, the primary target for treatment of THF is correcting underlying hyperthyroidism. However, since 
normalization of circulating TH and TSH takes many days, secondary target for treatment is managing symptoms [5,7].

\section{Clinical management strategies}

Hyperthyroidism management: The ATA/AACE Task Force guidelines recommend three effective and relatively safe initial treatment options for hyperthyroidism. The objective is to normalize circulating levels of TH and TSH. The three treatment options are (a) radioiodine therapy (RAI); (b) anti-thyroid drugs (ATD); and thyroidectomy [5].

Radioiodine therapy: Radioiodine therapy for hyperthyroidism has been in use since 1940s and conclusion about its efficacy rely on extensive clinical experience rather than randomized trials [68]. However, in clinical practice, RAI therapy varies widely, with key difference existing between North American and Europe. The rationale for RAI therapy is that iodine is a substrate for thyroid hormone synthesis and used to ablate functional thyroid tissue to eliminate the hyperthyroid state $[68,69]$. In the U.S, treatment goal for RAI is to achieve hypothyroid state while in Europe is to administer dose dependent on uptake scan to induce euthyroid state but the downside is higher incidence of persistent hyperthyroidism often requiring repeat treatment after six months. Most hyperthyroid patients will develop euthyroid state within 4 to 8 weeks of treatment, thus thyroid function should be evaluated at 2, 4 and 6 months post-treatment, and less frequently thereafter [69]. The decision to use RAI therapy over ATDs or surgery may depend on clinician and patient preference, underlying etiology, age, co-morbidities, smoking status and familial concerns such as planning pregnancy. Clinician preference varies greatly by location. In North America and Japan they prefer RAI therapy while in Europe prefer ATDs or surgery [70]. Contra-indication for RAI therapy include lactation, females panning for pregnancy within 4 to 6 months and inability to comply with radiation safety guidelines [68].

Anti-thyroid drugs: Clinicians and patients opting for ATDs therapy for hyperthyroidism should place higher value on the possible remission, avoiding of life-long treatment, avoiding the need for surgery, chronic exposure to radioactivity and relatively lower value of drug side effect, the need for continued monitoring and the possibility of disease recurrence [7]. Patients should be informed of ATDs side effects and the need to inform physician promptly to stop medication. Common side effects usually include pruritic rash, jaundice, acolic stools or dark urine, abdominal pain, nausea, fatigue, fever or pharyngitis. At initial presentation, blood tests should be conducted to assist in the interpretation of future laboratory findings prior to initiating therapy. Periodic (4 to 8 weeks) clinical and biochemical evaluation of levels of free TH and TSH is necessary to assess therapeutic efficacy, guide dosage and determine the achievement of euthyroid state [5,7].

Thyroidectomy: Thyroidectomy is the surgical removal of thyroid gland to lower the levels of serum TH and TSH. The target is to render the patient euthyroid as quickly and safely as possible. Clinician and patients opting for thyroidectomy should place relatively higher values on prompt and definitive control of hyperthyroidism, avoiding exposure to radioactivity, lower values on potential surgical risks and the need for lifelong thyroid hormone replacement [5]. Patients undergoing thyroidectomy should be rendered euthyroid using methimazole. Potassium iodide is recommended in the immediate pre-operative period. If it is not possible to render a patient euthyroid prior to surgery such as when the need for surgery is urgent or patient is allergic to ATDs, adequate treatment with beta-blocker and potassium iodide is recommended in the immediate pre-operative period [68].
Symptomatic management: THF is associated with elevated levels of serum TH and TSH as well as alterations in cardiac structure and function. Whereas normalization of the levels of serum TH and TSH is the primary therapeutic target, the treatment takes about 4 to 6 weeks warranting the clinical need for symptom management during anti-hyperthyroid management therapy. Symptomatic management targets to relieve symptom through reversing or controlling alterations in cardiac structure and function using the traditional HF medication [10]. ATA/AACE recommends beta-blocker as a safe and efficacious drug for symptom relief [7]. In patients whom diagnosis of THF is confirmed or strongly suspected, treatment with propranolol, atenolol, metoprolol or other beta-blocker is recommended until thyroid levels have normalized. The target is to help to slow down a rapid heart rate, prevent palpitations, lower systolic BP and reduce muscle weakness as well as improve the degree of irritability, emotional liability and exercise intolerance. $[5,10]$. Beta-blocker should be considered to all patients with symptomatic THF and to other thyrotoxic patients with resting heart rates $>90 \mathrm{bpm}$ or with concomitant cardiovascular disease. However, beta-blockers should be contraindicated in patients with bronchospastic asthma but in patients with quiescent bronchospastic asthma requiring heart rate control or in patients with mild obstructive disease, a non-selective beta-blocker could be used cautiously with careful monitoring of pulmonary status. Beta-blockers requires very high doses to relieve symptoms and reduce heart rate to normal levels [5]. For patients contraindicated for beta-blockers, calcium channel blockers (verapamil and diltiazem) taken orally are recommended for heart rate control. For THF patients with atrial fibrillation, digoxin or amiodarone should be considered to slow ventricular heart rate and chemical cardioversion respectively, and anticoagulants to reduce the risk of developing blood clots [10].

\section{Meta-analysis of treatment strategies}

The main therapeutic target for THF patients is normalization of serum free TH. At present, the ATA/AACE Task Force [5] recommends three strategies: RAI therapy, ATDs and thyroidectomy. All the three strategies have been well demonstrated to be efficacious in inducing euthyroidism in patients with thyrotoxicosis and HF. The recommendations emphasize on physician-patient consultation on the risks, benefits and personal preferences to inform the choice of an appropriate treatment strategy. Thus, the knowledge of favorable and unfavorable aspects of each treatment strategy is important to aid the choice of the most appropriate strategy. An important aspect of treatment is the risk of remission of hyperthyroid state, which if left untreated could induce cardiac manifestations. This meta-analysis of randomized clinical trials seeks to pool together findings on remission of hyperthyroidism following initial treatment to manage hyperthyroidism

Study selection and inclusion criteria: This meta-analysis was conducted and reported in accordance with referred Reporting Items for Systematic Reviews and Meta-Analyses (PRISMA) [71]. Pertinent studies evaluating treatment of THF patients to normalize serum TH levels were searched from online databases MEDLINE, EMBASE, CINAHL and PsycINFO. Further trials were identified through a manual search of bibliographies from the included studies and recent review articles. Search filters were restricted to randomized controlled trials (RCTs) with no publication year or language restriction. Key search terms used were thyrotoxicosis, hyperthyroidism, radioiodine, anti-thyroid drugs, thyroidectomy of surgery and remission. Studies were eligible if they were RCTS that: (a) included adult patients $(\geq 18$ years) diagnosed with thyrotoxicosis or hyperthyroidism with HF; (b) 
evaluated all the three treatment strategies - RAI therapy, ATDs and thyroidectomy; (c) and reported incidence of remission post-treatment; and (d) reported a follow-up of at least six months post-randomization. Two reviewers independently screened all titles and abstracts for eligibility and any disagreement about inclusion was resolved through discussion.

Data extraction and analysis: The following information categories were extracted from the included studies: (a) study characteristics (name of author, publication year and study design); (b) patients characteristics (population, female proportion and mean age); and (c) outcomes (follow-up period and percentage of remission). (Table 7). Dichotomous data was expressed as odds ratio (OR) and $95 \%$ Clearance Interval (CI). Continuous outcomes were expressed as mean change and standard deviation (SD) in outcomes between baseline and follow-up for all the three treatment strategies, and if not available the absolute mean and SD. Heterogeneity across studies was evaluated qualitatively through comparing features of individual studies and quantitatively using the $\mathrm{I}^{2}$ statistic. The findings from individual studies were pooled together for each outcome to give an overall estimate of treatment effect. A random model effect was used when $\mathrm{I}^{2}>50 \%$ and a fixed model when $\mathrm{I}^{2}<50 \%$.

Study characteristics and outcomes: Titles and abstracts of 456 studies retrieved from online search were reviewed and 17 potentially qualifying studies were selected for a further full-text search against the inclusion criteria. Eight (8) studies published between 1980 and 2008 that met the inclusion criteria were included in this meta-analysis. The combined patient population in the eight studies was 1,379, randomized into ATDs (613), thyroidectomy (427) and RAI (339). Total incidence of relapse was 275, with patients on ATDs having the highest percentage
(81\%) while thyroidectomy and RAI had comparable percentages at $9 \%$ and $10 \%$ respectively. Pooled analysis of the data indicates Rai has significantly lower rates of relapse compared to ATDs (OR: 0.113; 95\% CI, 0.0755 to $0.168 ; \mathrm{p}<0.001 ; \mathrm{I}^{2}=73.26 \%$ ) (Figure 3 ). There was no significant different between RAI and thyroidectomy (OR: 1.147; 95\% CI, 0.536 to $2.452 \mathrm{p}<0.724 ; \mathrm{I}^{2}=00.00$ ) (Figure 4). Thyroidectomy had a lower rate of relapse compared to ATDs (OR: 0.108; 95\% CI, 0.0726 to $0.160 ; \mathrm{p}<0.001 ; \mathrm{I}^{2}=78.08 \%$ ) (Figure 5).

\section{Discussion}

Prognosis of THF has been described as favorable compared to other forms of HF based on the potential to reverse and even cure its cardiac alterations and symptoms following re-establishment of euthyroid state [11]. However, some studies report incidences of incomplete reversal of myocardial function and associated with worse prognosis relative to patients with hypertension, valvular disease, HF or CAD [21-23]. Thus, the risk of relapse would suggest reduced treatment effectiveness or ab unfavorable prognosis. In the present meta-analysis, we sought to investigate the proportion of relapse in THF patients treated with ATDs, RAI or thyroidectomy. We defined relapse as the recurrence of hyperthyroidism (high levels of circulating $\mathrm{TH}$ ) > 12 months of therapy with ATD, RAI or thyroidectomy. The findings indicate ATDs has a significantly high relapse rate compared to RAI or thyroidectomy, while RAI and thyroidectomy have very low and comparable relapse proportion.

Understanding the risk of relapse of hyperthyroidism associated with THF therapy has clinical implications since the most effective treatment should eliminate hyperthyroidism as well as prevent its relapse. In fact, therapeutic primary goal of anti-hyperthyroidism therapy using RAI

Table 7. Summary of studies on efficacy of anti-thyroid treatment in THF patients

\begin{tabular}{|c|c|c|c|c|c|c|c|}
\hline \multirow{2}{*}{ 1st Author [Ref\#] } & \multirow{2}{*}{ Year } & \multicolumn{2}{|c|}{ ATDs } & \multicolumn{2}{|c|}{ Thyroidectomy } & \multicolumn{2}{|c|}{ RAI } \\
\hline & & Sample & Relapse & Sample & Relapse & Sample & Relapse \\
\hline Sugrue et al. [72] & 1980 & 162 & 90 & 266 & 16 & 43 & 1 \\
\hline Berglund et al. [73] & 1991 & 83 & 36 & 23 & 2 & 106 & 5 \\
\hline Mengistu et al [74] & 1992 & 47 & 3 & 6 & 1 & NR & NR \\
\hline Torring et al. [75] & 1996 & 68 & 36 & 37 & 4 & 39 & 8 \\
\hline Pineda et al [76] & 1998 & 88 & 58 & 37 & 2 & 70 & 6 \\
\hline Leary et al [77] & 1999 & 74 & 50 & 5 & 1 & 38 & 10 \\
\hline Tutuncu et al. [78] & 2006 & 43 & 28 & 6 & 6 & 7 & 7 \\
\hline Laurberg et al. [79] & 2008 & 48 & 2 & 47 & 3 & 36 & NR \\
\hline
\end{tabular}

ATDs: Anti-Thyroid Drugs; FUP: Follow-up Period; RAI: Radioiodine Therapy

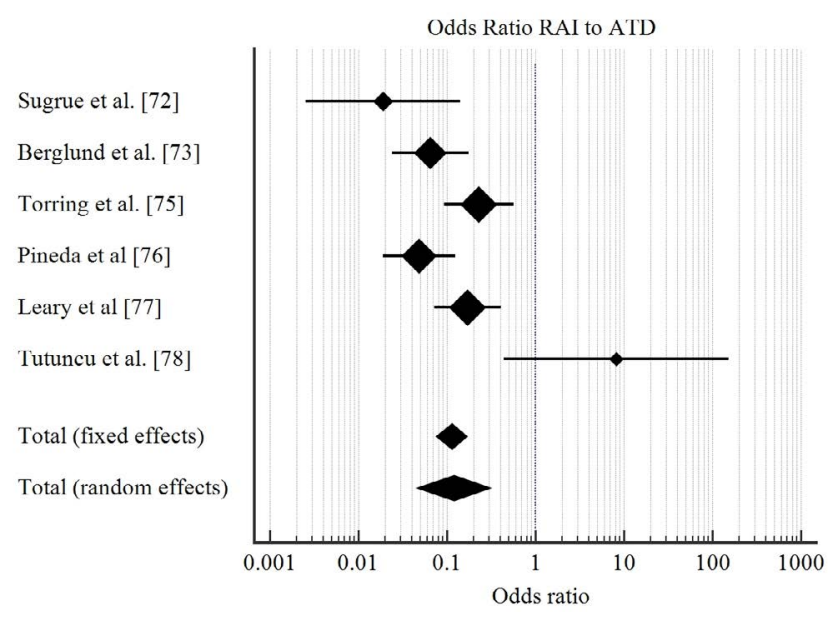

Figure 3. Forest plot showing odds ratio of relapse between RAI and ATDs 


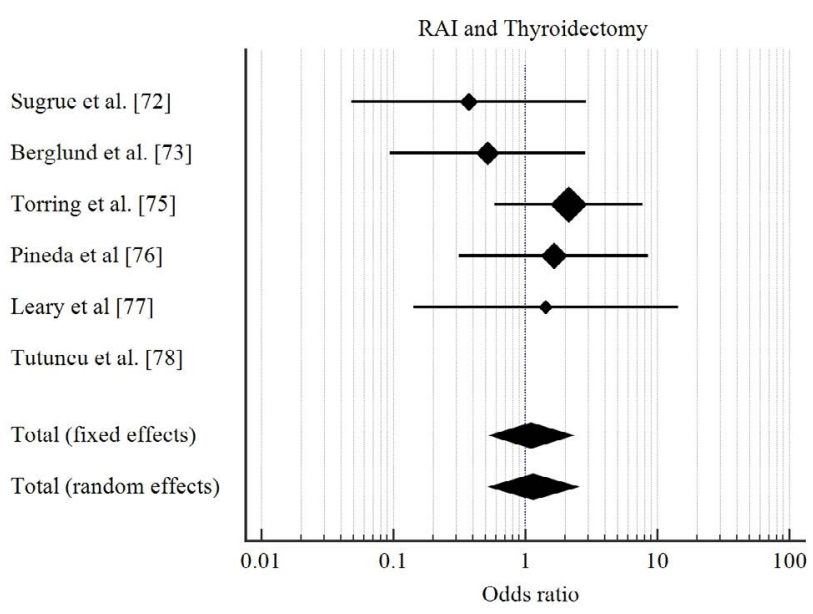

Figure 4. Forest plot showing odds ratio of relapse between RAI and thyroidectomy

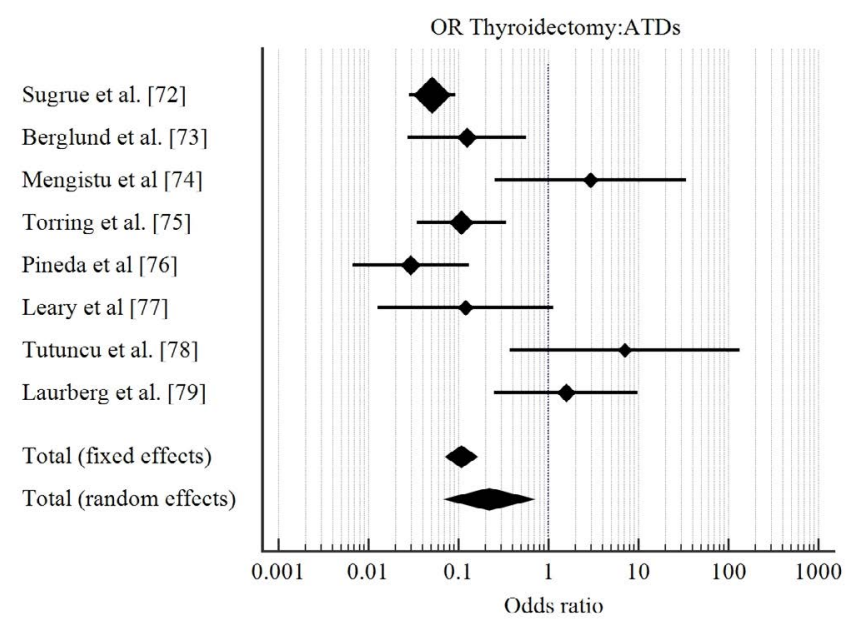

Figure 5. Forest plot showing ODDA ratio of relapse between thyroidectomy and ATDs

and/or thyroidectomy is to induce hypothyroidism and necessitate life-long thyroid hormone replacement therapy $[5,11,68]$. However, since the choice of therapy depends on shared decision-making between clinician and patients, some patients may prefer treatment that allows the thyroid gland to resume normal functioning to avoid lifelong thyroid hormone therapy $[68,70]$. In such a case, medication using ATDs carry an advantage over both RAI and thyroidectomy. This advantage may also explain the preference for RAI in North America and ATDs in Europe and Japan [68]. Caution should also be observed when interpreting the present findings since other clinically relevant factors such as dose and duration of treatment for ATDs and RAI, and the type of surgery (total or subtotal thyroidectomy) could have an impact on treatment effect on the prevention of relapse. The a lack of high-quality evidence on the effect of dosage and duration of treatment on prevention of relapse, and the relationship between hyperthyroidism relapse and cardiovascular events in THF patients warrants additional randomized controlled trials in the two areas. Findings from such studies would improve physician-patients shared decision-making on the choice of the optimum treatment modality for THF.

\section{Conclusion}

Thyrotoxic heart failure (THF) is a cardiac disorder characterized by myocardial damage and high cardiac output due to the toxic effect of high serum thyroid hormones (TH), which alter myocardial energy production, intracellular metabolism and myofibril contractility. Its exact epidemiology is not well established partly because its clinical assessment lacks a thorough exclusion of other potential etiologies. Its prognosis is relatively favorable because of a potential reversal of cardiac function after normalization of serum TH. Duration of hyperthyroidism, male gender, presentence of atrial fibrillation, and higher pre-treatment levels of serum TH signify a poor prognosis. The main pathophysiologic mechanisms are alterations in hemodynamics and myocardial contractility leading to rhythm disturbances, increased heart rate, high cardiac output and ultimately ventricular failure. It is more prevalent among the elderly with co-occurring cardiovascular diseases. Its typical signs and symptoms include palpitation, cardialgia, dyspnea, tachycardia at rest and during sleep, and significantly increased heart rate at minimal physical exertion. Diagnosis lacks specific guidelines. Currently, diagnosis relies on (a) objective laboratory evidence of high circulating TH and TSH; (b) reversal of symptoms after achieving euthyroid state; and (c) the exclusion of other potential etiologies through echocardiographic assessment of alterations in LV structure and function. There is need for large-scale clinical trials to develop specific clinical guidelines to improve diagnosis and disease monitoring. At present, the primary clinical management target is to normalize serum TH and TSH levels through radioiodine therapy, antithyroid medication and thyroidectomy. Beta-blocker may be used in combination with any of the above therapies to ameliorate symptoms of THF.

\section{References}

1. Levine SA, Sturgis CC (1924) Hyperthyroidism masked as heart disease. The Boston Medical and Surgical Journal 190: 233-237. [Crossref]

2. Panagoulis C, Halapas A, Chariatis E, Driva PO, Matsakas EV (2008) Hyperthyroidism and the heart. Hellenic J Cardiol 49: 169-175. [Crossref]

3. Osuna PM, Udovcic M, Sharma MD (2017) Hyperthyroidism and the Heart. Methodist Debakey Cardiovasc J, 13: 60-63. [Crossref]

4. Vydt T, Verhelst J, De Keulenaer G (2006) Cardiomyopathy and thyrotoxicosis: tachycardiomyopathy or thyrotoxic cardiomyopathy? Acta cardiologica 61: 115-117. [Crossref]

5. Bahn RS, Burch HB, Cooper DS, Garber JR, Greenlee MC, Klein I, Laurberg P, McDougall IR, Montori VM, Rivkees SA (2011) Hyperthyroidism and other causes of thyrotoxicosis: management guidelines of the American Thyroid Association and American Association of Clinical Endocrinologists. Thyroid 21: 593-646. [Crossref]

6. Sahay RK (2011) Thyrotoxicosis. J Assoc Physicians India 59: 26-31. [Crossref]

7. Ross DS, Burch HB, Cooper DS, Greenlee MC, Laurberg P, Maia AL, Rivkees SA, Samuels M, Sosa JA, Stan MN, Walter MA (2016) 2016 American Thyroid Association guidelines for diagnosis and management of hyperthyroidism and other causes of thyrotoxicosis. Thyroid 26: 1343-1421. [Crossref]

8. Richardson P (1996) Report of the 1995 World Health Organization/International Society and Federation of Cardiology. Task force on the definition and classification of cardiomyopathies. Circ 93: 841-842. [Crossref]

9. Ademolu AB (2017) Thyrotoxic cardiomyopathy: a study of three cases. Gerontol \& Geriatric stud 1: 1-4. [Crossref]

10. Choudhury RP, MacDermot J (1998) Heart failure in thyrotoxicosis, an approach to management. Br J Clin Pharmacol 46: 421-424. [Crossref]

11. Babenko AY, Bairamov AA, Grineva EN, Ulupova EO (2012) Thyrotoxic Cardiomyopathy. In Cardiomyopathies-From Basic Research to Clinical Management 2012. InTech. 553-580. [Crossref]

12. Forfar JC, Muir AL, Sawers SA, Toft AD (1982) Abnormal left ventricular function in hyperthyroidism: evidence for a possible reversible cardiomyopathy. $N$ Engl J Med 307: 1165-1170. [Crossref]

13. Hrnciar J (2002) Cor thyreotoxicum. Part I: New findings about its etiopathogenesis and diagnosis. Overview of problems based on 35 years' experience. Vntr Lek 48: 3844. [Crossref] 
Albakri A (2018) Thyrotoxic heart failure: A review of clinical status and meta-analysis of electrocardiogram diagnosis and medical clinical management methods

14. Roffi M, Cattaneo F, Topol EJ (2003) Thyrotoxicosis and the cardiovascular system: subtle but serious effects. Cleveland Clinic journal of medicine 70: 57-63. [Crossref]

15. Siu CW, Yeung CY, Lau CP, Kung AW, Tse HF (2007) Incidence, clinical characteristics and outcome of congestive heart failure as the initial presentation in patients with primary hyperthyroidism. Heart 93: 483-487. [Crossref]

16. Brauman A, Algom M, Gilboa Y, Ramot Y, Golik A, Stryjer D (1985) Mitral valve prolapse in hyperthyroidism of two different origins. Heart 53: 374-377. [Crossref]

17. Mohr-Kahaly S, Kahaly G, Krause U, Erbel R, Beyer J (1987) Graves' disease and mitral valve prolapse. Acta Endocrinologica 116): S86-. [Crossref]

18. Evangelopoulou ME, Alevizaki M, Toumanidis S, Piperingos G, Mavrikakis M et al. (1999) Mitral valve prolapse in autoimmune thyroid disease: an index of systemic autoimmunity?. Thyroid 9: 973-977. [Crossref]

19. Burggraaf J, Tulen JH, Lalezari S, Schoemaker RC, De Meyer PH et al. (2001) Sympathovagal imbalance in hyperthyroidism. Am J Physiol Endocrinol Metab 281: E190-E195. [Crossref]

20. Cacciatori V, Bellavere F, Pezzarossa A, Dellera A, Gemma ML et al. (1996) Power spectral analysis of heart rate in hyperthyroidism. J Clin Endocrinol Metab 81: 28282835. [Crossref]

21. Ortmann C, Pfeiffer H, Du Chesne A, Brinkmann B (1999) Inflammation of the cardiac conduction system in a case of hyperthyroidism. Int J. Legal. Med 112: 271-274. [Crossref]

22. Martí V, Ballester M, Rigla M, Narula J, Bernà L et al. (1997) Myocardial damage does not occur in untreated hyperthyroidism unless associated with congestive heart failure. Am Heart J 134: 1133-1137. [Crossref]

23. Osman F, Gammage MD, Sheppard MC, Franklyn JA (2002) Cardiac Dysrhythmias and Thyroid Dysfunction-The Hidden Menace? Clin Endocrinol Metab 87: 963-967. [Crossref]

24. Metso S, Jaatinen P, Huhtala H, Auvinen A, Oksala H, Salmi J (2007) Increased cardiovascular and cancer mortality after radioiodine treatment for hyperthyroidism. $J$ Clin Endocrinol Metab 92: 2190-2196. [Crossref]

25. Mitchell JE, Hellkamp AS, Mark DB, Anderson J, Johnson GW et al. (2013) Thyroid function in heart failure and impact on mortality. JACC: Heart Failure 1: 48-55. [Crossref]

26. Pasqualetti G, Niccolai F, Calsolaro V, Bini G, Caraccio N et al. (2017) Relationship between thyroid dysfunction and heart failure in older people. Journal of Gerontology And Geriatrics 65: 184-191. [Crossref]

27. Klein I, Danzi S (2007) Thyroid disease and the heart. Circ 116: 1725-1735. [Crossref]

28. Toft AD, Boon NA (2000) Thyroid disease and the heart. Heart 84: 455-460. [Crossref]

29. Demers LM, Spencer CA (2003) Laboratory medicine practice guidelines: laboratory support for the diagnosis and monitoring of thyroid disease. Clinical endocrinology 58: 138-140. [Crossref]

30. Baloch Z, Carayon P, Conte-Devolx B, Demers LM, Feldt-Rasmussen U et al. (2003) Laboratory medicine practice guidelines. Laboratory support for the diagnosis and monitoring of thyroid disease. Thyroid 13: 3-126. [Crossref]

31. DeGroot LJ, Nakai A, Sakurai A, Macchia E (1989) The molecular basis of thyroid hormone action. Journal of endocrinological investigation 12: 843-861. [Crossref]

32. Brent GA (1994) The molecular basis of thyroid hormone action. $N$ Engl J Med 331 847-853. [Crossref]

33. Maia AL, Kim BW, Huang SA, Harney JW, Larsen PR (2005) Type 2 iodothyronine deiodinase is the major source of plasma T 3 in euthyroid humans. J Clin Invest 115: 2524-2533. [Crossref]

34. Bianco AC, Salvatore D, Gereben B, Berry MJ, Larsen PR (2002) Biochemistry, cellular and molecular biology, and physiological roles of the iodothyronine selenodeiodinases. Endocrine Rev 23: 38-89. [Crossref]

35. Mintz GU, Pizzarello RO, Klein I (1991) Enhanced left ventricular diastolic function in hyperthyroidism: noninvasive assessment and response to treatment $J$ Clin Endocrinol Metab 73: 146-150. [Crossref]

36. Hartong R, Wang N, Kurokawa R, Lazar MA, Glass CK et al. (1994) Delineation of three different thyroid hormone-response elements in promoter of rat sarcoplasmic reticulum $\mathrm{Ca} 2+\mathrm{ATPase}$ gene. Demonstration that retinoid $\mathrm{X}$ receptor binds 5 'to thyroid hormone receptor in response element 1. J Biol Chem 269: 13021-13029. [Crossref]

37. Kiss E, Jakab G, Kranias EG, Edes I (1994) Thyroid hormone-induced alterations in phospholamban protein expression. Regulatory effects on sarcoplasmic reticulum Ca2+ transport and myocardial relaxation. Circ Res 75: 245-251. [Crossref]
38. Davis PJ, Davis FB (2002) Nongenomic actions of thyroid hormone on the heart. Thyroid 12: 459-466. [Crossref]

39. Hiroi Y, Kim HH, Ying H, Furuya F, Huang Z et al. (2006) Rapid nongenomic actions of thyroid hormone. Proc Natl Acad Sci 103: 14104-14109. [Crossref]

40. Park KW, Dai HB, Ojamaa K, Lowenstein E, Klein I et al. (1997) The direct vasomotor effect of thyroid hormones on rat skeletal muscle resistance arteries. Anesthesia \& Analgesia.85: 734-738. [Crossref]

41. Danzi S, Klein I (2004) Thyroid hormone and the cardiovascular system. Minerva endocrinologica 29: 139-150. [Crossref]

42. Vargas F, Moreno JM, Rodríguez-Gómez I, Wangensteen R, Osuna A et al. (2006) Vascular and renal function in experimental thyroid disorders. Eur J Endocrinol 154 197-212. [Crossref]

43. Napoli R, Biondi B, Guardasole V, Matarazzo M, Pardo F et al. (2005) Impact of hyperthyroidism and its correction on vascular reactivity in humans. Circ 104: 30763080. [Crossref]

44. Kuzman JA, Gerdes AM, Kobayashi S, Liang Q (2005) Thyroid hormone activates Akt and prevents serum starvation-induced cell death in neonatal rat cardiomyocytes. $J \mathrm{Mol}$ Cell Cardiol 39: 841-844. [Crossref]

45. Ladenson PW, Sherman SI, Baughman KL, Ray PE, Feldman AM (1992) Reversible alterations in myocardial gene expression in a young man with dilated cardiomyopathy and hypothyroidism. Proc Natl Acad Sci 89: 5251-5255. [Crossref]

46. Lowes BD, Minobe W, Abraham WT, Rizeq MN, Bohlmeyer TJ et al. (1997) Changes in gene expression in the intact human heart. Downregulation of alpha-myosin heavy chain in hypertrophied, failing ventricular myocardium. J Clin Invest 100: 2315-2324. [Crossref]

47. Danzi S, Klein I, Portman MA (2005) Effect of triiodothyronine on gene transcription during cardiopulmonary bypass in infants with ventricular septal defect. Am J Cardiol 95: 787-789. [Crossref]

48. Klein I, Hong C (1986). Effects of thyroid hormone on cardiac size and myosin conten of the heterotopically transplanted rat heart. J Clin Invest 77: 1694-1698. [Crossref]

49. Biondi B, Palmieri EA, Fazio S, Cosco C, Nocera M et al. (2000) Endogenous subclinical hyperthyroidism affects quality of life and cardiac morphology and function in young and middle-aged patients J Clin Endocrinol Metab. 85: 4701-4705. [Crossref]

50. Dörr M, Wolff B, Robinson DM, John U, Lüdemann J et al. (2005) The association of thyroid function with cardiac mass and left ventricular hypertrophy. J Clin Endocrinol Metab 90: 673-677. [Crossref]

51. Bielecka-Dabrowa A, Mikhailidis DP, Rysz J, Banach M (2009) The mechanisms of atrial fibrillation in hyperthyroidism. Thyroid research $2: 4$. [Crossref]

52. Whitner TE, Hudson CJ, Smith TD, Littmann L (2005) Hyperthyroidism: presenting as isolated tricuspid regurgitation and right heart failure. Tex Heart Inst J 32: 244-245. [Crossref]

53. Soh MC, Croxson M (2008) Fatal thyrotoxic cardiomyopathy in a young man. BMJ 337:a531. [Crossref]

54. Osman F, Franklyn JA, Holder RL, Sheppard MC, Gammage MD (2007) Cardiovascular manifestations of hyperthyroidism before and after antithyroid therapy: a matched case-control study. J Am Coll Cardiol 49: 71-81. [Crossref]

55. Ponikowski P, Voors AA, Anker SD, Bueno H, Cleland JG, et al. (2016) 2016 ESC Guidelines for the diagnosis and treatment of acute and chronic heart failure: The Task Force for the diagnosis and treatment of acute and chronic heart failure of the European Society of Cardiology (ESC) Developed with the special contribution of the Heart Failure Association (HFA) of the ESC. Eur Heart J 37: 2129-2200. [Crossref]

56. Goyal S, Goyal V (2016). A study of electrocardiographic changes in thyroid disorders International Journal of Medical Research and Review, 4: 486-490. [Crossref]

57. Fadel BM, Ellahham S, Lindsay Jr J, Ringel MD, Wartofsky L et al. (2000) Hyperthyroid heart disease. Clinical cardiology 23: 402-408. [Crossref]

58. Anakwue RC, Onwubere BJ, Ikeh V, Anisiuba B, Ike S et al. (2015) Echocardiographic assessment of left ventricular function in thyrotoxicosis and implications for the therapeutics of thyrotoxic cardiac disease. Ther Clin Risk Manag 11:189-200. [Crossref]

59. Oliveros-Ruiz L, Vallejo M, Diez Canseco LF, Cárdenas M, Hermosillo JA (2013). Determinants of thyrotoxic cardiomyopathy recovery. BioMed research international 2013. [Crossref]

60. Walsh EP, Alexander ME, Cecchin FR (1992) Electrocardiography and introduction to electrophysiologic techniques. Nadas' Pediatric cardiology. Philadelphia, Hanley \& Belfus Inc/Mosby 117-158. [Crossref] 
61. Satpathy PK, Diggikar PM, Sachdeva V, Laddha M, Agarwal A et al. (2013) Lipid profile and electrocardiographic changes in thyroid dysfunction. Medical Journal of Dr. DY Patil University 6: 250-253. [Crossref]

62. Schiller NB, Shah PM, Crawford M, DeMaria A, Devereux R et al. (1989) Recommendations for quantitation of the left ventricle by two-dimensional echocardiography "J Am Soc Echocardiogr 2: 358-367. [Crossref]

63. Fazio S, Palmieri EA, Lombardi G, Biondi B (2004). Effects of thyroid hormone on the cardiovascular system. Recent progress in hormone research 59: 31-50. [Crossref]

64. Mehta PA, Dubrey SW (2009) High output heart failure. QJM: An International Journal of Medicine 102: 235-241. [Crossref]

65. Hoffman I, Lowrey RD (1960). The electrocardiogram in thyrotoxicosis. Am J Cardiol 6: 893-904. [Crossref]

66. Parisi AF, Hamilton BP, Thomas CN, Mazzaferri EL (1974) The short cardiac preejection period: an index to thyrotoxicosis. Circ 49: 900-904. [Crossref]

67. Osman F, Franklyn JA, Holder RL, Sheppard MC, Gammage MD (2007) Cardiovascular manifestations of hyperthyroidism before and after antithyroid therapy: a matched case-control study. J Am Coll Cardiol 49: 71-81. [Crossref]

68. Ross DS (2011) Radioiodine therapy for hyperthyroidism. N Engl J Med 364: 542-550. [Crossref]

69. O'Connell J, Hayes F (2011) Radioiodine therapy for hyperthyroidism. Irish medical journal. [Crossref]

70. Wartofsky L, Glinoer D, Solomon B, Nagataki S, Lagasse R et al. (1991) Differences and similarities in the diagnosis and treatment of Graves' disease in Europe, Japan, and the United States. Thyroid 1: 129-135. [Crossref]

71. Moher D, Shamseer L, Clarke M, Ghersi D, Liberati A et al. (2015) Preferred reporting items for systematic review and meta-analysis protocols (PRISMA-P) 2015 statement. Systematic reviews 4: 1. [Crossref]
72. Sugrue D, McEvoy M, Feely J, Drury MI (1980) Hyperthyroidism in the land of Graves: results of treatment by surgery, radioiodine and carbimazole in 837 cases. QJM: An International Journal of Medicine 49: 51-61. [Crossref]

73. Berglund J, Christensen SB, Dymling JF, Hallengren B (1991) The incidence of recurrence and hypothyroidism following treatment with antithyroid drugs, surgery or radioiodine in all patients with thyrotoxicosis in Malmö during the period 1970-1974. J. Intern. Med 229: 435-442. [Crossref]

74. Mengistu M (1992) A prospective study of 110 Ethiopians with thyrotoxicosis. East Afr Med J 69: 515-519. [Crossref]

75. Torring O, Tallstedt L, Wallin G, Lundell G, Ljunggren JG et al. (1996) Graves' hyperthyroidism: treatment with antithyroid drugs, surgery, or radioiodine--a prospective, randomized study. Thyroid Study Group. J Clin Endocrinol Metab 81: 2986-2993. [Crossref]

76. Pineda G, Arancibia P, Mejía G (1998) Treatment of Basedow-Graves' hyperthyroidism: retrospective analysis after 30 years. Revista Medica de Chile 126: 953-962. [Crossref]

77. Leary AC, Grealy G, Higgins TM, Buckley N, Barry DG et al. (1999) Long-term outcomes of treatment of hyperthyroidism in Ireland. Ir J Med Sci 168: 47-52. [Crossref]

78. Tutuncu NB, Tutuncu T, Ozgen A, Erbas T (2006) Long-term outcome of Graves disease patients treated in a region with iodine deficiency: relapse rate increases in years with thionamides. $J$ Natl Med Assoc 98: 926-930. [Crossref]

79. Laurberg P, Wallin G, Tallstedt L, Abraham-Nordling M, Lundell G et al. (2008) TSHreceptor autoimmunity in Graves' disease after therapy with anti-thyroid drugs, surgery, or radioiodine: a 5-year prospective randomized study. Eur J Endocrinol 158: 69-75. [Crossref]

Copyright: (C2018 Albakri A. This is an open-access article distributed under the terms of the Creative Commons Attribution License, which permits unrestricted use, distribution, and reproduction in any medium, provided the original author and source are credited. 